\title{
Analisa Persebaran Sarang Penyu Hijau (Chelonia Mydas) Berdasarkan Vegetasi Pantai Di Pantai Sukamade Merubetiri Jawa Timur
}

\author{
Argina Dewi. S*, Hadi Endrawati, Sri Redjeki \\ Program Studi Ilmu Kelautan, Fakultas Perikaan dan Ilmu Kelautan, Universitas Diponegoro \\ Kampus Tembalang, Semarang 50275 Telp/ Fax 024-7474698 \\ Email: argina16@gmail.com
}

\begin{abstract}
Abstrak
Aktivitas manusia yang merusak habitat pantai peneluran Penyu Hijau mengakibatkan penurunan populasi Penyu Hijau. Penataan tempat bertelur penyu (nesting site) dianggap hal yang penting untuk meningkatkan kembali populasi penyu hijau. Penataan tempat bertelur bagi penyu meliputi kondisi biologi. Kondisi biologi pantai peneluran merupakan hal yang penting untuk diperhatikan. Kondisi biologi pantai peneluran salah satunya adalah kondisi vegetasi pantai. Secara biologi kehadiran penyu pada suatu pantai dipengaruhi kondisi ekosistem dan komposisi vegetasi pantai. Vegetasi dianggap memiliki peranan penting dalam aktivitas peneluran penyu karena memberikan rasa nyaman pada lingkungan sekitar peneluran. Tujuan penelitian ini adalah untuk mengetahui persebaran sarang peneluran Penyu Hijau (Chelonia mydas) berdasarkan vegetasi pantai dan mengetahui jenis vegetasi yang ada disekitar sarang Penyu Hijau. Penelitian ini menggunakan metode deskriptif. Data yang diambil meliputi data penyu bertelur, jarak sarang terhadap vegetasi dan profil vegetasi pantai. Penelitian ini dilakukan pada pukul 20.00 WIB dan 04.30 WIB sesuai dengan jadwal monitoring penyu petugas di lapangan. Hasil dari penelitian ini menunjukkan bahwa aktivitas peneluran Penyu Hijau (Chelonia mydas) lebih banyak ditemukan pada sektor dengan keadaan lingkungan bervegetasi dengan jenis vegetasi Pandanus tectorius, Baringtonia asiatica, Hibiscus tilaceus. Sedangkan pada sektor yang hanya ditumbuhi vegetasi rambat seperti Ipoemoea pes - caprae Penyu Hijau tidak ditemukan melakukan aktifitas peneluran.
\end{abstract}

Kata Kunci : Penyu Hijau, Vegetasi, Pantai Sukamade.

\begin{abstract}
Human activity destroys beach mullet in egg laying of Green Turtle which because the decreasing Green Turtle. Settting of egg laying place for Green Turtle (nesting site) is considered matters for increasing the population of Green Turtle. Biologist condition of as laying egg beach is beach vegetation condition in biology. One of the presence of turtle in a beach is influenced by ecosystem condition and beach vegetation condition and beach vegetation comparition vegetation is considered to have important role in egg laying activity. The purpose of this experiment for getting to know spreading of Green Turtle's nest based on beach vegetation and knowing the type of vegetation there around the Green Turtle. This experiment used descriptive method. Date taken is included turtle's laying egg, distance among the nest to vegetation and beach vegetation profile. This experiment done 8 p.m and 4.30 p.m as the Green Turtle monitoring schedule by the employee in the field. The result of this experiment shows that Green Turtle laying egg activity is often found in the station with environment with vegetation criteria for 19 Green Turtles. Meanwhile in the station with is only found 3 Green Turtles. The result of this experiment indicate that the spawning activity Green Turtle (Chelonia mydas) is more common in the sector to the state of vegetation with kind of vegetation is Pandanus tectorius, Hibiscus tilacues, Baringtonia asiatica while the sector only vegetation propagation spawning activity Green Turtles less.
\end{abstract}

Keywords : Green Turtle, Vegetation, Sukamade Beach

\section{PENDAHULUAN}

Di dunia terdapat 7 jenis penyu, tetapi hanya 6 jenis penyu yang ditemukan di perairan Indonesia. Keenam jenis penyu tersebut ialah
Penyu Belimbing (Dermochyles coriacea), Penyu Sisik (Eretmocheyls imbiricata), Penyu Hijau (Chelonia mydas), Penyu Tempayan (Caretta caretta), Penyu Pipih (Natator depressa) dan 
Penyu Lekang (Lepidocheyls olivaceae). Satu jenis penyu yang tidak ditemukan di Indonesia adalah Penyu Kempi (Lepidocheyls kempi). Jenis ini hanya dapat ditemukan diperairan Amerika Latin (Dahuri, 2003).

Salah satu jenis penyu yang paling banyak ditemukan di Indonesia adalah Penyu Hijau (Chelonia mydas). Jenis ini dapat ditemukan di seluruh perairan bagian tropis dan subtropis di seluruh dunia dengan ciri yang mudah dikenali yaitu bentuk paruh yang kecil dan tumpul (Jansen, 2006). Penyu Hijau mampu bermigrasi dalam jarak yang jauh di sepanjang kawasan Samudera Hindia, Samudera Pasifik dan Asia Tenggara.

Salah satu tempat yang menjadi lokasi pendaratan serta peneluran Penyu Hijau ialah Pantai Sukamade Kawasan Taman Nasional Meru Betiri Kabupaten Banyuwangi, Jawa Timur. Menurut Balai Taman Nasional Meru Betiri (1998), lokasi ini sering ditemukan aktivitas penyu bertelur sebagian besar merupakan jenis Penyu Hijau (Chelonia mydas).

Namun saat ini populasi Penyu Hijau mulai berkurang bahkan hampir punah. Hal tersebut salah satunya dikarenakan aktivitas manusia yang merusak habitat peneluran Penyu Hijau. Pesatnya perkembangan pariwisata saat ini juga merupakan salah satu penyumbang terbesar kerusakan yang terjadi pada habitat peneluran Penyu Hijau. Selain itu rusaknya vegetasi pantai yang diakibatkan oleh aktivitas manusia ataupun kerusakan yang disebabkan oleh faktor lain diduga turut serta menjadi penyebab turunnya populasi Penyu Hijau. Jenis - jenis vegetasi seperti Pandanus tectorius, Baringtonia asiatica, Cemara Laut merupakan jenis - jenis vegetasi yang memiliki pengaruh yang besar terhadap aktivitas peneluran penyu (Roemantyo, 2012). Menurut (Ferry dkk, 2013) populasi Penyu Hijau di Indonesia terus menurun, penurunan populasi Penyu Hijau di alam disebabkan oleh pencurian telur dan anak penyu semakin meningkat, lalu lintas air yang semakin ramai oleh para nelayan serta para pengunjung dan banyaknya vegetasi yang rusak akibat terjadinya abrasi yang mengakibatkan terjadinya pen-degradasi habitat penyu. Oleh karena itu perlu dilakukan upaya konservasi Penyu Hijau.

Salah satu upaya untuk meningkatkan populasi Penyu Hijau adalah dengan melakukan penataan kembali tempat peneluran (nesting site). Penataan tempat peneluran merupakan salah satu cara untuk menjaga keberadaan populasi Penyu Hijau. Salah satu bagian yang dianggap penting dari habitat peneluran Penyu Hijau ialah vegetasi pantai, karena dengan adanya vegetasi mampu menjaga suhu dan tingkat kelembaban dalam suatu area tempat peneluran.

Tujuan penelitian ini adalah untuk mengetahui persebaran sarang peneluran Penyu Hijau (Chelonia mydas) berdasarkan vegetasi pantai dan mengetahui jenis vegetasi yang ada disekitar sarang Penyu Hijau. Dalam hal ini akan dilakukan analisa pengaruh keberadaan vegetasi dalam setiap stasiun peneluran terhadap frekuensi aktivitas peneluran.

\section{MATERI DAN METODE}

Materi yang digunakan dalam penelitian ini adalah sarang peneluran Penyu Hijau (Chelonia mydas).Metode yang digunakan dalam penelitian ini adalah metode survey deskriptif. Metode yang memberikan gambaran keadaan secara sistematik (Notoadmojo, 2002)

\section{Metode Penentuan Lokasi Pengamatan}

Penentuan lokasi pengamatan menggunakan metode purposive random sampling yaitu penentuan dengan pertimbangan tertentu oleh peneliti (Notoatmodjo, 2002). Pertimbangan yang digunakan berdasarkan keberadaan vegetasi. Pantai Sukamade Meru Betiri Jawa Timur memiliki panjang pantai $\pm 3,2 \mathrm{Km}$. Balai Taman Nasional Meru Betiri telah menetapkan pembagian sektor guna memudahkan dalam pengamatan aktivitas peneluran penyu yaitu sebanyak 32 sektor.

Berdasarkan hasil observasi tersebut juga didapatkan hasil bahwa pada sektor $1-24$ terdapat vegetasi. Sedangkan pada sektor $25-32$ tidak ditemukan vegetasi, dengan keadaan tersebut dapat dibagi menjadi sektor dengan keadaan lingkungan bervegetasi dan sektor dengan keadaan lingkungan tidak bervegetasi. Namun dalam penelitian ini yang akan diamati adalah sektor dengan keadaan lingkungan bervegetasi (sektor 1 - sektor 24)

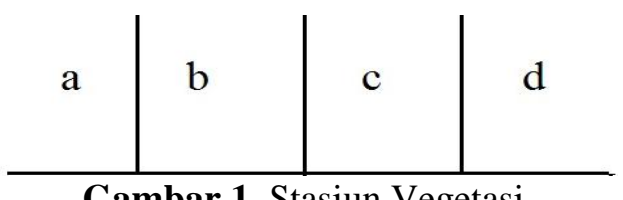

Gambar 1. Stasiun Vegetasi

Sedangkan dalam menganalisa jenis - jenis vegetasi yang ada pada setiap sektor tersebut. Setiap sektor akan dibagi kedalam 4 stasiun kecil (a, b, c dan d) (gambar. 1). Hal tersebut bertujuan untuk mempermudah dalam mengamati setiap jenis yang ada pada setiap sektor. Setiap sektor yang memiliki panjang $100 \mathrm{~m}$ akan dibagi 
kedalam 25 meter (a), 25 meter (b), 25 meter (c) dan 25 meter (d).

\section{Pencatatan Jumlah Sarang Penyu Hijau (Chelonia mydas)}

Pencatatan jumlah sarang Penyu Hijau (Chelonia mydas) dilakukan pada pukul 20.00 23.00 WIB dan dilanjutkan pukul 04.30 - 05.30 WIB hal tersebut dilakukan karena aktivitas penyu banyak ditemukan pada waktu tersebut.

\section{Pencatatan Jenis dan Jumlah Vegetasi}

Pencatatan jenis vegetasi pantai dan jumlah vegetasi dilakukan pada area yang telah ditentukan dengan menggunakan transek dan dilakukan pengulangan sebanyak 3 kali.

\section{Pengukuran Jarak Sarang Terhadap Vegetasi}

Pengukuran jarak sarang penyu terhadap vegetasi dengan menggunakan roll meter dengan cara menarik garis tegak lurus dari sarang sampai ke vegetasi yang menaungi sarang dan berada paling dekat keberadaannya terhadap sarang peneluran

Pada gambar 2 terdapat huruf $\mathrm{J}, \mathrm{S}$ dan $\mathrm{V}$ seperti pada keterangan $\mathrm{V}$ merupakan vegetasi pantai yang terdapat pada suatu stasiun. S merupakan sarang penyu ditemukan dan $\mathbf{J}$ adalah jarak antara vegetasi terluar terhadap sarang Penyu Hijau yang ditemukan.

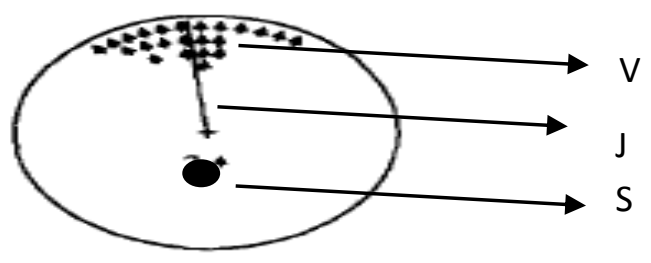

Gambar 2. Penghitungan Jarak

\section{Analisis Data}

Analisis data yang dilakukan meliputi vegetasi pantai peneluran dan data kondisi biologi Penyu Hijau. Data tersebut akan menunjukkan gambaran pengaruh vegetasi pantai di Pantai Sukamade terhadap sarang peneluran Penyu Hijau.

\section{HASIL DAN PEMBAHASAN \\ Data Sarang Penyu Hijau (Chelonia mydas)}

Selama penelitian berlangsung, yang dilakukan selama 20 hari di Pantai Sukamade Meru Betiri Jawa Timur ditemukan sarang penyu sebanyak 29 sarang. Sarang Penyu Hijau tersebut ditemukan dibeberapa sektor. Namun Penyu Hijau lebih banyak ditemukan pada sektor 1 dan 13.

Aktivitas Penyu Hijau (Chelonia mydas) banyak ditemukan pada malam hari hal tersebut dikarenakan suhu dan kelembaban subtract yang tinggi pada malam hari. Menurut Chaerudin dan Azis (1984) Penyu akan melakukan akitivitas peneluran pada malam hari karena suhu dan kelembaban subtrat yang diciptakan pada malam hari relatif lebih tinggi. Selain itu menurut Ali (2011) pada malam hari keadaan pantai cenderung gelap dan tenang sehingga aktivitas peneluran penyu lebih banyak ditemukan pada malam hari.

\section{Jumlah dan Jenis Vegetasi Setiap Sektor}

Didapatkan hasil vegetasi yang ada pada setiap sektor ialah Pandanus tectorius, Hibiscus tilaceus, Baringtonia asiatica, Ficus Bejamina dan ditemukan jenis vegetasi rambat Spinifex littorius, Ipoemoe- pes caprae, kemeladian, rumput teki seperti dapat dilihat pada gambar 3 .

Keanekaragaman jenis vegetasi pantai lebih banyak ditemukan pada sektor $1-13$, pada sektor- sektor tersebut didapati vegetasi jenis Pandanus tectorius, Hibiscus tilaceus, Baringtonia asiatica, Ficus Bejamina. Sedangkan pada sektor $14-24$ jenis vegetasi yang ada lebih sedikit. Pada sektor - sektor tersebut hanya dapat ditemukan vegetasi jenis Pandanus tectorius dan ditemukan vegetasi rambat jenis Ipoemoe- pes caprae, rumput teki, Spinifex littorius dan kemeladian.

Jenis vegetasi pantai memiliki peranan penting dalam persebaran sarang di Pantai Sukamade Meru Betiri Jawa Timur. Hal tersebut terbukti bahwa sarang Penyu Hijau yang lebih banyak ditemukan pada sektor 1 - 13 dengan jumlah sebanyak 19 sarang Penyu Hijau. Sedangkan pada sektor 14 - 24 sarang yang ditemukan hanya sebanyak 8 sarang Penyu Hijau.

Banyaknya jenis vegetasi pantai dalam satu area juga dapat dikaitkan dengan kelembaban dan suhu subtrat lingkungan tersebut. Berdasarkan penghitungan dilapangan pada sektor $1-13$ kelembaban berkisar pada nilai $73,6 \%-74,1 \%$ dengan suhu $26,2^{\circ} \mathrm{C}-26.3^{\circ} \mathrm{C}$. Sedangkan pada sektor 14 - sektor 24 kelembaban 70,9\% - 71,4\% dan suhu $27,0^{\circ} \mathrm{C}-27,5^{\circ} \mathrm{C}$. Menurut Ferry dkk (2013) penyu melakukan aktivitas peneluran pada kondisi lingkungan pada suhu dan kelembaban subtrat masing - masing $26,4^{\circ} \mathrm{C}$ dan $73 \%$.

Selain itu pada sektor $14-24$ dimana terdapat hamparan vegetasi jenis Spinifex littorius atau lari - larian dan Ipoemoea - pes caprae tidak pernah ditemukan Penyu Hijau melakukan 
aktivitas peneluran didaerah tersebut. Hal tersebut dapat dikarenakan Spinifex littorius dan jenis vegetasi rambat Ipoemoea - pes caprae sangat menganggu aktivitas peneluran Penyu Hijau karena sifatnya yang merambat sehingga menyulitkan penyu dalam melakukan penggalian lubang. Menurut Agus (1989) jenis vegetasi Ipoemoea - pes caprae dan Spinifex littorius yang memiliki formasi memanjang dan malang melintang serta jenis Spinifex littorius yang berduri mengganggu aktivitas peneluran Penyu Hijau, sehingga harus dilakukan pemantauan terhadap pertumbuhan vegetasi jenis ini.

\section{Jarak Sarang Terhadap Vegetasi}

Jarak sarang yang ditemukan terhadap vegetasi berkisar antara $0,3-3,5$ meter. Penyu akan memilih untuk meletakkan telur - telurnya dengan jarak yang cukup dekat dengan vegetasi dan jauh dari pantai. Menurut G. C Hays (1995) Penyu Hijau akan melakukan aktivitas peneluran pada lingkungan bervegetasi atau sampai 2 meter masuk kedalam zona vegetasi pantai. Menurut Susilowati (2012) sarang Penyu Hijau lebih banyak ditemukan pada jarak 2 - 4 meter dari vegetasi terluar dan jauh dari pantai. Gambar 4.

\section{Vegetasi yang Banyak Ditemukan}

Vegetasi yang banyak ditemukan pada setiap sarang peneluran ialah Pandanus tectorius dan Baringtonia asiciata seperti yang dapat dilihat pada gambar 5 .

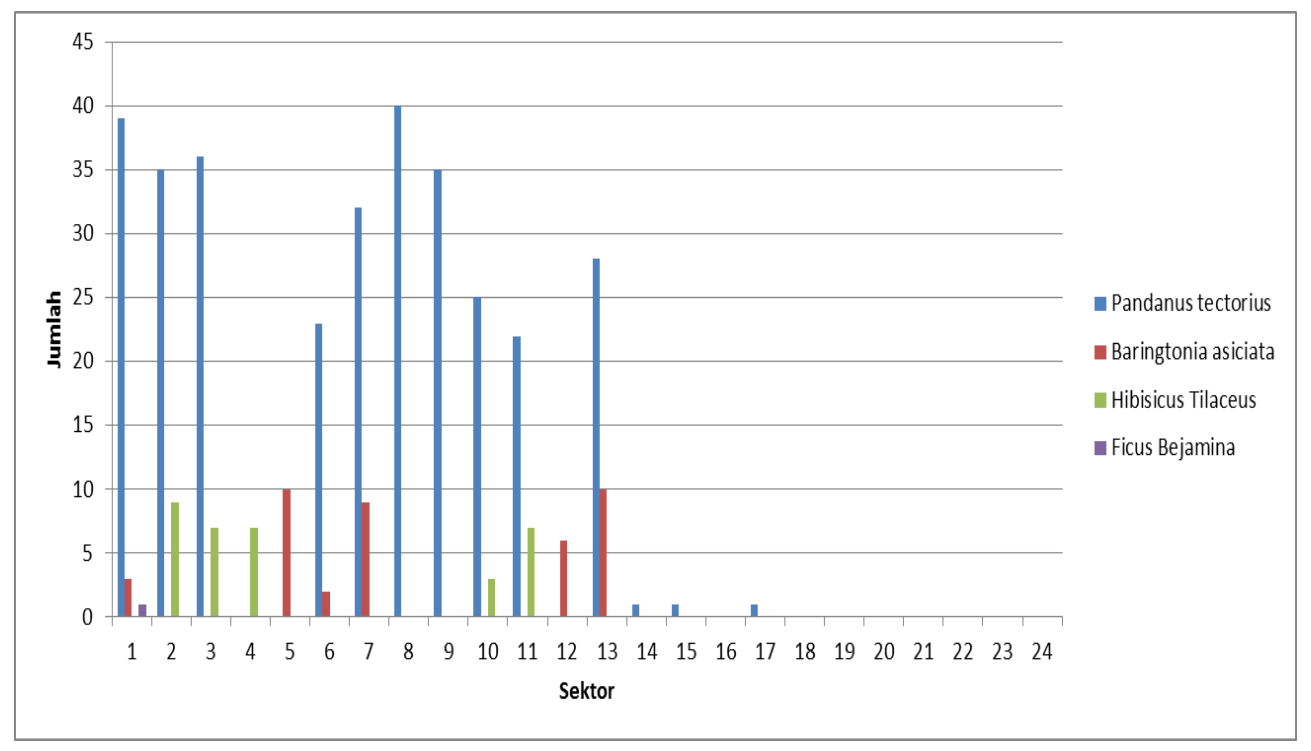

Gambar 3. Jenis dan Jumlah Vegetasi sektor 1-24

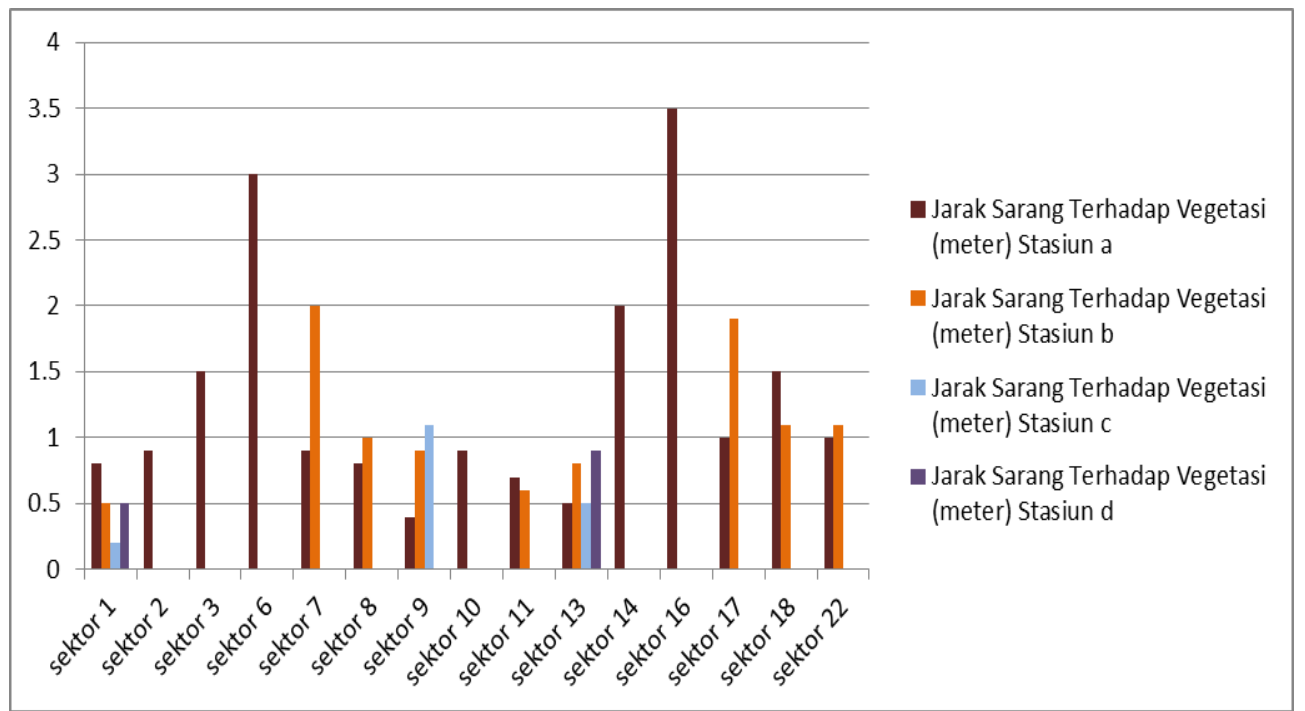

Gambar 4. Jarak Sarang 


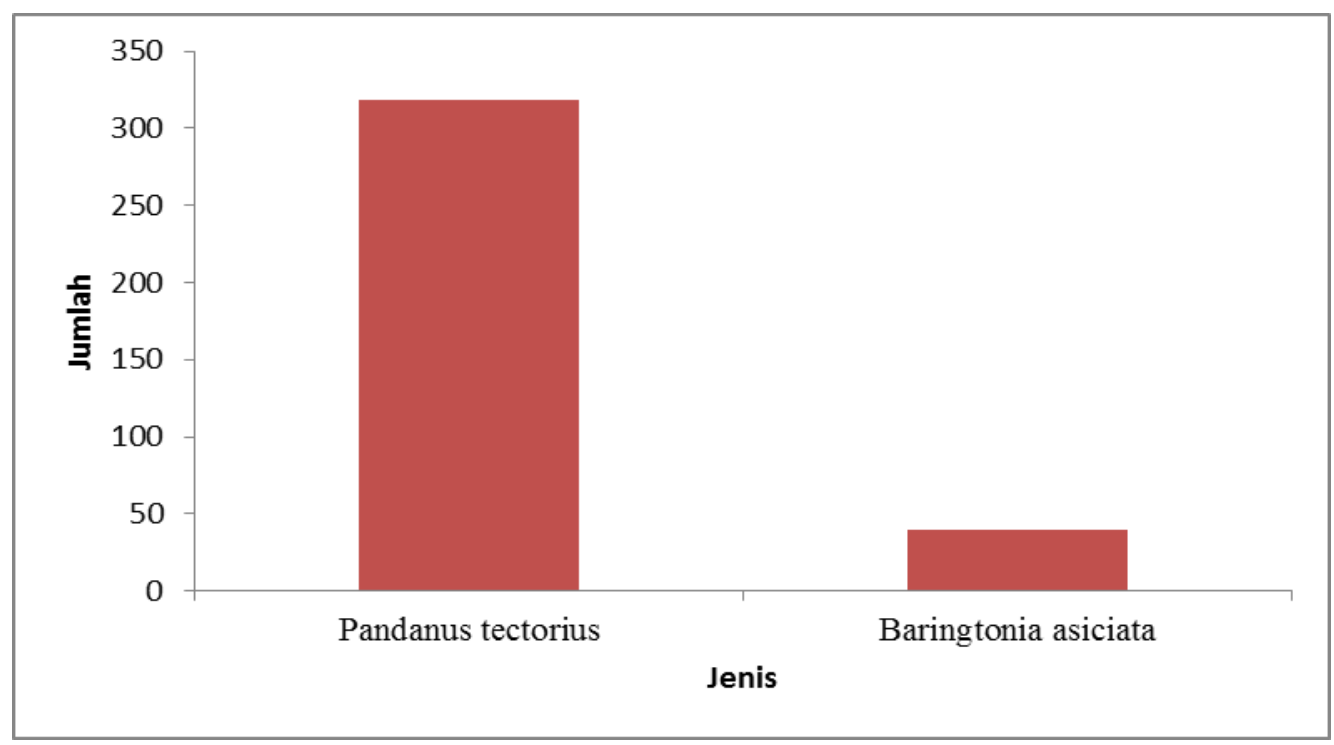

Gambar 5. Jenis Vegetasi yang Banyak Ditemukan

Berdasarkan pengamatan Penyu Hijau banyak ditemukan melakukan aktivitas peneluran pada vegetasi jenis Pandanus tectorius dan Baringtonia asiciata karena vegetasi tersebut memiliki sistem perakaran yang kuat yang mampu menyanggah runtuhan pasir selama proses penggalian. Hal tersebut sesuai dengan pernyataan Nuitja (1992) yang mengatakan vegetasi pantai sangat berpengaruh terhadap lingkungan penelurannya dikarenakan akar vegetasi yang dapat mengikat butiran pasir dan menghindari terjadinya keruntuhan pasir sehingga akan dapat mempermudah penyu dalam melakukan penggalian dan proses penelurannya. Lebih lanjut menurut Rosalina dalam Casdika (1998), penyu banyak menyukai pembuatan sarang dibawah naungan pandan laut (Pandanus tectorius) karena perakaran pandan laut meningkatkan kelembapan dan memberikan kestabilan pada pasir serta tidak menganggu saat penggalian lubang sarang penyu.

\section{KESIMPULAN}

Penyu Hijau (Chelonia mydas) lebih banyak ditemukan melakukan aktivitas peneluran pada kondisi pantai peneluran dengan vegetasi yang beragam jenisnya dengan jenis Baringtonia asaitica, Pandanus tectorius, Hibiscus tilaceus. Sedangkan pada kondisi pantai dengan keadaan vegetasi rambat seperti pada vegetasi jenis Ipoemoe pes - caprae Penyu Hijau tidak ditemukan melakukan aktivitas peneluran.

\section{UCAPAN TERIMA KASIH}

Penulis menyampaikan terima kasih kepada semua pihak yang telah membantu dalam penelitian dan kepada dewan redaksi Journal of Marine Research (JMR) yang telah memberikan pengarahan dan petunjuk dalam jurnal ilmiah ini serta semua pihak yang telah memberikan bantuan dan fasilitas dalam penulisan jurnal ilmiah ini.

\section{DAFTAR PUSTAKA}

Agus, P. 1989. Pengelolaan Habitat dan Satwa Penyu Laut. Media Konservasi. Vol II (2)

Ali, Z.M. 2004. Karya Ilmiah Pelestarian Penyu Hijau di Pantai Selatan Tasikmalaya. Karya Ilmiah Tentang Pelestarian Penyu Hijau : Tasikmalaya

Balai Taman Nasional Meru Betiri.1998. Rencana Pengembangan Kawasan Konservasi Taman Nasional Meru Betiri Sebagai Pusat Pengembangan dan Penelitian Penyu. Bagian Kegiatan dan Peningkatan Usaha Konservasi di Dalam dan di Luar Kawasan Hutan. Sub Balai Konservasi Sumberdaya Alam Jawa Timur II

Bustard, R.H. 1972. Natural History and Conservation, Taplinger Publishing Company, New York.

Carr, A. 1972. Great Reptiles, Great Enigmas, Audubon No. 2, pp 504-515.

Dahuri, R. 2003. Keanekaragaman Hayati Laut Aset Pembangunan Berkelanjutan Indonesia. Gramedia Pustaka Utama Jakarta

Dermawan, A., Nyoman S. N., Dedi S., Matheus H.H., Mirza D.K., Syamsul B.L., Rofi A., M. Khazali., Mimi M. \& Poppi L., Wahjuhardini, Setiabudiningsih, dan Ali M., 2009. Pedoman Teknis Pengelolaan Konservasi Penyu. Direktorat Konservasi dan 
Taman Nasional Laut, Direktorat Jenderal Kelautan, Pesisir dan Pulau-Pulau Kecil, Departemen Kelautan dan Perikanan RI. Jakarta.

Endik, C. 1998. Pengaruh Slinitas Terhadap Pertumbuhan Tukik Penyu Hijau Chelonia mydas L. di Pantai Pangumbahan Kabupaten Sukabumi

Erkyansyah. 1997. Penetasan Telur Penyu Hijau (Chelonia mydas) Semi Alami pada 2 Pasir Penutupan Sarang yang Berbeda di Pantai Bandulu Kabupaten Anyer Jawa Barat. Fakultas Biologi - Universitas Nasional. Jakarta.

Ernst, C., Barbour, R. \& Lovich, J. 1994. Turtles of the United States and Canada. Washington and London : Smithsonian Institution.

Faishal, 2015. Studi Habitat Pantai Peneluran Pantai Sukamade Meru Betiri Jawa Timur. Universitas Diponegoro

Ferry A., Syafruddin, S., \& Sarma, S. 2013. Habitat Tempat Bertelur Penyu Hijau (Chelonia mydas) di Kawasan Taman Wisata Alam Sungai Liku Kabupaten Sambas Kalimantan Barat. Universitas Tanjungpura

G.c. Hays., Mackay, A., Adams, C.R., Mortimer, J.S., Speakman, J.R. \& Boerema, M. 1995. Nest Site Selction By Sea Turtles. USA. Captiva Concervation.

Hirth. H. 1971. Synopsys of Biologi Data on The Green Turtle, Chelonia mydas (Linnaeus, 1758). FAO, Fisheries Synopsys.

Ka, U.W.H.T. 2000. Mengenal Penyu. Terjemahaan Akil Yusuf, Yayasan Alam Lestari, Jakarta

Limpus, C.J. 1979. Notes Rates Growth. Marine Conservation Rates of Wild Turtles. Marine Turtles News Letter. Australia.

Lomowa \& Sona, V.T. 2012. Ekologi Tumbuhan. Universitas Mulawarman: Samarinda

Miller, J.D. 1997. Reproduction In Sea Turtles. In: Lutz, P. L dan Musick, J. A (eds). The
Biology of Sea Turtle. CRC Press, Boca Raton. Pp. 51-82.

Nazir, M. 1983. Metode Penelitian. PT. Ghalia Indonesia, Jakarta. $622 \mathrm{hlm}$.

Notoatmodjo, S. 2002. Metodologi Penelitian Kesehatan. Rineka Cipta. Jakarta. 138 - 140.

Nuitja, I.N.S. 1992. Biologi dan Ekologi Pelestarian Penyu Laut. Institut Pertanian Bogor Press. Bogor.

Polunin, N. 1990. Pengantar Geografi Tumbuhan dan Beberapa Ilmu Serumpun. UGM Press, Yogyakarta. (Diterjemahkan oleh Gembong Tjitrosoepomo). $797 \mathrm{hlm}$.

Barreto, R., Matthew \& Godfrey, H. 1994. Beach Vegetation and Seafinding Orientation of Turtle Hatchlings. Elsevier. Canada.

Rebel, T.P. 1974. Sea Turtle and The Turtle Industry of West Indies, Florida, and The Gulf of Mexico. University of Miami Press. Coral Gables. Florida. USA.

Roemantyo., Nastiti, Andriani, S., \& Wiadnyana, Ngurah, N. 2012. Struktur dan Komposisi Vegetasi Sekitar Sarang Penyu Hijau (Chelonia mydas Linnaeus) Pantai Pangumbahan, Sukabumi, Jawa Barat. LIPI. Jakarta

Sub Balai KSDA Jawa Timur II, 1991. Laporan Pelestarian dan Pembinaan Populasi Penyu Di Pantai Sukamade Taman Nasional Meru betiri tahun 1990, Jember.

Widiastuti, H. 1998. Karakteristik Biofisik Habitat Peneluran Penyu Hijau (Chelonia mydas) di Pantai Citerem dan Pangumbahan, kabupaten Sukabumi, Propinsi Jawa Barat. Fakultas Perikanan dan Kelautan. Institut Pertanian Bogor. Bogor.

Yusuf, A. 2000. Mengenal Penyu. Yayasan Alam Lestari. Jakarta.

Yusri, S. 2003. Kondisi Habitat dan Vegetasi Pantai Peneluran Penyu Hijau (Chelonia mydas) di Suaka Margasatwa Cikepuh, Sukabumi, Jawa Barat. FMIPA. UI Jakarta. 